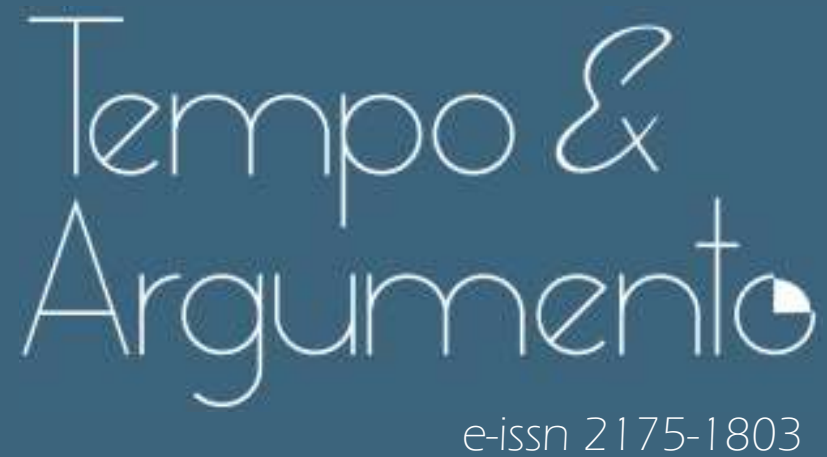

O ensino da ditadura civil-militar no tempo presente pelo olhar dos professores mestres do ProfHistória

\title{
- Alessandra Carvalho
}

Doutora em Sociologia pela Universidade Federal do Rio de Janeiro (UFRJ)

Professora do Colégio de Aplicação e do Programa de Pós-Graduação em Ensino de História (ProfHistoria) da Universidade Federal do Rio de Janeiro (UFRJ).

Rio de Janeiro, RJ - BRASIL

lattes.cnpq.br/2765565145395915

ale-carvalho@uol.com.br

(D) orcid.org/0000-0002-5010-8314

Para citar este artigo:

CARVALHO, Alessandra. O ensino da ditadura civil-militar no tempo presente pelo olhar dos professores mestres do ProfHistória. Tempo e Argumento, Florianópolis, v. 13, n. 33, e0103, maio/ago. 2021.

do http://dx.doi.org/10.5965/2175180313332021e0103

Recebido: 05/03/2021

Aprovado: 23/05/2021 


\title{
O ensino da ditadura civil-militar no tempo presente pelo olhar dos professores mestres do ProfHistória
}

\begin{abstract}
Resumo
O texto investiga o ensino da história da ditadura civil-militar brasileira no tempo presente em 18 dissertações de mestrado defendidas por professores da educação básica entre os anos de 2014 e 2019 no Mestrado Profissional em Ensino de História ProfHistória. A análise parte de duas premissas. A primeira enfatiza o tempo presente vivido por professores e alunos como elemento articulador das aulas de História e práticas docentes; ao mesmo tempo, sublinha o aprofundamento da reflexão sobre os imperativos políticos e éticos da escrita e do ensino da História. A partir de itens específicos das dissertações, são analisados os significados atribuídos ao ensino da história da ditadura civil-militar situando-os no contexto específico conformado pelos impactos das políticas de memórias do Estado e pelo fortalecimento da ação pública de grupos que justificam ou negam a ditadura em interação com a crise política vivida no período. Os professores produziram reflexões e proposições que defenderam a potencialidade da história escolar para desenvolver nos estudantes a capacidade de compreender a produção social e a disputa entre diferentes memórias sobre a ditadura e, também, problematizar as narrativas que a justificam ou negam. Essa potencialidade foi explorada através de atividades que acionam grande diversidade de materiais didáticos, métodos da escrita da História e a participação ativa dos alunos no processo de ensino-aprendizagem. Os professores também afirmaram as finalidades sociais da história escolar ao conceber o ensino da ditadura como mecanismo para forjar o compromisso dos estudantes com o regime democrático.
\end{abstract}

Palavras-chave: Ensino de história; ditadura civil-militar; mestrado profissional em ensino de história - ProfHistória.

\section{ProfHistória graduate teachers' perspectives on teaching civil-military dictatorship in present time}

\begin{abstract}
This paper exams how Brazilian civil-military dictatorship period is taught at Brazilian basic education. It is based on the analysis of 18 final projects ' history teachers wrote to achieve their masters' degrees, between 2014 and 2019. This master is part of the program "Professional Master in History Teaching - ProfHistória." The analysis considers two premises: first, current events affect the way teachers and students articulate their understanding in history classes; second, reflection on political and ethical principles affects deeply the writing and teaching of history nowadays. Considering specific parts of final projects, this paper analyzes the meaning teachers employ regarding the teaching of civil-military dictatorship history. It explores the political context marked by the effects of State policies of memories and the strengthening of narratives that justify or deny the dictatorship, as well as political crisis that marked those years. Teachers' reflections and proposals defend history in basic education as a potential tool to develop abilities such as the understanding of social production and conflicts between different memories concerning dictatorial past. It also can help students to criticize narratives that denies or justifies dictatorship today. The activities produced by teachers are based in varied didactic sources and academical History methodologies and aim to engage students in teaching-learning process. Teachers also conceives the teaching of civil-military dictatorship history in basic education as a social commitment to reinforce support to democratic regime among students.
\end{abstract}

Keywords: History teaching; civil-military dictatorship; Professional Master in History Teaching - ProfHistória. 
Em uma análise sobre as experiências de ensino da história da última ditadura civil-militar na Argentina desenvolvidas desde a década de 1980, a historiadora Sandra Raggio afirmou: "Dime qué piensas de la dictadura y te diré qué te parece la democracia" (RAGGIO, 2017, p. 6). Essa provocação destaca a centralidade das demandas vividas no presente para a compreensão dos processos sociais de elaboração de memórias e atribuição de significado aos períodos ditatoriais, nos quais os sujeitos produzem distintas narrativas que se relacionam com seus embates político-ideológicos, vivências geracionais e construção de identidades. Por outro lado, embates, vivências e identidades se reestruturam continuamente ao longo do tempo, concorrendo para a produção de novas pautas e projetos para a democracia que atuam nas aproximações que se faz com o passado.

Neste texto, é proposta a inserção de um terceiro vértice para a reflexão que une ditadura e democracia - o ensino de História na educação básica. Se Raggio sublinha a indissociabilidade entre presente e passado na construção de sentido para ambos, introduzimos a questão de como essa dinâmica forja impactos na história escolar no que se refere à definição de suas finalidades e de suas práticas didáticas. Pode-se estabelecer, assim, que a provocação aqui se configura da seguinte maneira: diga-me o que você pensa da ditadura e eu te direi como te parece a democracia e para que serve o ensino de História.

A proposição acima se baseia em duas premissas. A primeira delas é a consideração do tempo presente de alunos e professores como elemento catalisador das diversas variáveis envolvidas no ensino de História. De acordo com Ilmar Mattos, a aula de História é

criação individual e coletiva a um só tempo; criação sempre em curso, que permanentemente renova um objeto de ensino em decorrência de novas leituras, de outras experiências vividas, da chegada de novos alunos, dos encontros acadêmicos e das conversas com os colegas de ofício, do surgimento de novos manuais didáticos, das decisões emanadas das instâncias educacionais e das questões, dos desafios e das expectativas geradas pelo movimento do mundo no qual vivemos, em sua dimensão local ou global. (MATTOS, 2007, p. 14) 
Aproximando-se da questão pelo prisma da constituição dos saberes dos professores e dos currículos, Ana Maria Monteiro indicou direção semelhante ao afirmar que

os professores ensinam História no tempo presente, a partir de demandas emergentes que estão registradas nas diretrizes e propostas curriculares vigentes, exames vestibulares, avaliações sistêmicas, questionamentos dos alunos, tradições escolares, e que emergem dos debates políticos da sociedade na qual estão inseridos. Produzem o currículo ao articular os vários saberes que eles e seus alunos dominam com referências culturais que circulam no contexto em pauta e os fluxos do conhecimento científico. (MONTEIRO, 2015, p. 168)

Desse modo, as aulas de História são sempre elaboradas no tempo presente, entendido não como recorte temporal específico, mas no sentido de que as interações e os significados conferidos ao passado devem ser compreendidos a partir de sua relação com o tempo vivido por professores e estudantes. É como parte de um contexto curricular, acadêmico e político que os docentes criam suas aulas, selecionando sujeitos, materiais, questões e referências historiográficas e priorizando operações cognitivas de acordo com o que estabelecem como objetivos para seus alunos (CARNOVALE; LARRAMENDY, 2010; GONZALEZ, 2018). Essa premissa impõe, também, o reconhecimento da produção permanente de novos usos do passado ditatorial pela história escolar, de acordo com o que apresentam os estudantes, as diretrizes curriculares, a historiografia, os debates políticos - em suma, o movimento do mundo em suas dimensões local e global ao qual se refere Mattos.

A segunda premissa é a emergência, no campo da História, de um chamamento à reflexão acerca de seu caráter político e ético, relacionado à demanda por novas formas de escrever e ensinar História que considerem a crítica a paradigmas tradicionais de Estado e de nação e se debrucem sobre novos sujeitos, levando em conta subjetividades, identidades e memórias plurais (SILVA, 2017). Esse movimento tensiona as maneiras pelas quais historiadores e professores concebem os aspectos definidores de seu campo científico e sua função social, em meio a uma arena pública marcada pela presença crescente de narrativas do passado produzidas por não historiadores (TURIN, 2018). Isso se torna especialmente evidente em temas como as ditaduras, que lidam com 
violência, sofrimento, violações de direitos humanos, trauma, injustiça, democracia, cidadania e muitas disputas de memória. Como sublinha Caroline Bauer (2017), aí entram em cena as tensões entre cientificidade e militância e entre profissionalização e compromisso social, que atravessam a escrita e o ensino de História no tempo presente e pressionam historiadores e professores a buscar um equilíbrio particular e a agir.

É a partir dessas considerações que este texto analisa os significados que professores da educação básica atribuem ao ensino da ditadura civil-militar, relacionando-os às finalidades que definem para o ensino de História nos tempos atuais. Que equilíbrios são forjados entre as demandas da cientificidade e o compromisso social na história escolar? Quais ações docentes derivam desse processo? Como ditadura e democracia dialogam atualmente nas aulas de História? Com essas questões, tomamos como fonte as dissertações realizadas por professores de História da educação básica entre os anos de 2014 e 2019, defendidas no Mestrado Profissional em Ensino de História (ProfHistória).

As dissertações de mestrado do ProfHistória e a ditadura civil-militar Antes de apresentar as dissertações, é importante descrever brevemente a estrutura e o funcionamento do ProfHistória. O programa foi criado no ano de 2013, no âmbito das políticas de formação de professores da educação básica implementadas pela Coordenação de Aperfeiçoamento de Pessoal de Nível Superior (Capes). Estabelecido como um mestrado em rede nacional, o ProfHistória teve sua primeira turma em 2014, com 12 universidades públicas e privadas associadas. Nas turmas de 2016, 2018 e 2019, foram 27 instituições em todo o país, que aumentaram para 39, na turma iniciada no ano de 2020. Entre 2016, quando ocorreram as primeiras defesas de dissertação, até o final de 2020, foram inseridos na Plataforma Sucupira 667 trabalhos, segundo levantamento realizado em 15 de fevereiro de 2021.

Em acordo com a regulação federal, é obrigatório que o mestrando esteja atuando como professor de História nos níveis fundamental e médio das redes pública ou privada para que possa cursar o ProfHistória. Por isso, desde 2014, centenas de docentes da educação básica passaram a frequentar a pós- 
graduação das universidades, confrontando as pesquisas em ensino de História com suas questões, experiências e saberes. Ao mesmo tempo, a produção acadêmica relativa à didática, aprendizagem, educação das relações étnicoraciais, teoria da História, entre tantos outros temas, foi imediatamente incorporada aos saberes e às práticas dos mestrandos nos diversos espaços educativos onde atuam. Alunos e egressos do ProfHistória também têm participado cada vez mais dos eventos organizados pelas Associação Nacional de História (Anpuh) e Associação Brasileira de Ensino de História (Abeh), ampliando a presença dos professores da educação básica nos debates da área e a interação entre escola e universidade (OLIVEIRA; OLIVEIRA, 2020).

Por resultarem de um mestrado profissional, as dissertações do ProfHistória apresentam características específicas que corroboraram sua escolha para objeto de análise. Em primeiro lugar, as questões de pesquisa geralmente têm como origem as experiências profissionais dos mestrandos e os interrogantes que delas surgem. Assim, as dissertações nos remetem diretamente ao cotidiano vivido pelos professores de História nas escolas e, também, fora dela - em espaços como museus e sítios urbanos e rurais -, e ressaltam aquilo que os desafia como docentes, transformado em temas de investigação. Ao mesmo tempo, nesses textos, seus autores descrevem, cotejam e analisam essas experiências em diálogo com os fluxos do conhecimento científico da área.

Também é indicado que os mestrandos elaborem, como resultado da pesquisa, uma dimensão propositiva, com vistas a ser utilizada por professores de História e/ou estudantes da educação básica. Esta tem assumido uma infinidade de formatos tais como material didático ou paradidático em papel e digital, sites, jogos, intervenções em espaços públicos, documentários, oficinas, aulas de campo, centros de memória, cadernos para professores e sequências didáticas... Essas dissertações constituem, portanto, um material que expressa as questões candentes para os professores em seu trabalho diário e os encaminhamentos construídos por eles no tempo presente a partir da pesquisa em ensino de História. 
Para o exame pretendido aqui, procedemos à identificação das dissertações que tratam do tema da ditadura civil-militar estabelecendo algumas delimitações. A base de dados foi montada com os trabalhos defendidos pelos integrantes das turmas do ProfHistória iniciadas nos anos de 2014 e 2016, o que nos permitiu ter acesso ao conjunto de pesquisas finalizadas por cada turma entre 2016 e 2019. A partir desse critério, foi feita uma busca na Plataforma Sucupira e no Portal eduCapes, em junho de 2020, utilizando o termo "ditadura", que deveria constar no título, no resumo ou nas palavras-chave dos trabalhos. 0 quadro 1 apresenta o quantitativo de dissertações encontradas no conjunto dos trabalhos de cada turma:

QUADRO 1 - Turma de entrada no ProfHistória, número de dissertações com o tema da ditadura civil-militar e período de desenvolvimento

\begin{tabular}{|c|c|c|}
\hline TURMA & $\begin{array}{c}\text { NÚMERO DE DISSERTAÇÕES SOBRE } \\
\text { DITADURA/TOTAL DE DISSERTAÇÕES } \\
\text { DEFENDIDAS }\end{array}$ & $\begin{array}{c}\text { PERÍODO DE DESENVOLVIMENTO } \\
\text { DA PESQUISA }\end{array}$ \\
\hline 2014 & $6 / 129$ & $2014-2017$ \\
\hline 2016 & $12 / 331$ & $2016-2019$ \\
\hline
\end{tabular}

Fonte: Plataforma Sucupira e Portal eduCapes. Busca realizada no dia 13 de junho de 2020.

Ao todo, foram identificadas 18 dissertações que corresponderam aos critérios de busca em um total de 460 trabalhos, o que sinaliza que a pesquisa sobre o ensino da história da ditadura civil-militar não ocupou grande espaço entre as questões dos mestrandos. Todavia, é importante indicar que os resultados apresentados acima não contemplam todas as dissertações que desenvolveram reflexões e atividades sobre esse período histórico no ProfHistória. Há trabalhos nos quais os temas principais de investigação foram uma determinada metodologia de ensino-aprendizagem ou perspectiva teórica, que se desdobraram em uma proposição didática elaborada em torno da história da ditadura. Foi o caso de dissertações sobre ensino híbrido, consciência histórica, uso da música e gênero, que não inseriram o termo "ditadura" no título, no resumo ou nas palavras-chave (ALMEIDA, 2016; NOGUEIRA, 2018; PIRES, 2016; RODRIGUES, 2016). O mapeamento dessas pesquisas implicaria consultar, para além do título, palavras-chave e resumo, o sumário de todas as dissertações e, 
por essa razão, elas não foram aqui contempladas, embora possam oferecer importantes subsídios para a reflexão proposta.

O quadro 2 apresenta as informações institucionais dos 18 trabalhos identificados:

QUADRO 2 - Informações sobre as dissertações do ProfHistória com o tema da ditadura civil-militar

\begin{tabular}{|c|c|c|c|}
\hline TíTULO & $\begin{array}{l}\text { ANO DE } \\
\text { DEFESA }\end{array}$ & $\begin{array}{l}\text { INSTITUIÇÃO } \\
\text { ASSOCIADA }\end{array}$ & AUTORIA \\
\hline $\begin{array}{l}\text { 1. Memória da resistência à ditadura } \\
\text { militar brasileira: guia para utilização } \\
\text { de filmes em sala de aula }\end{array}$ & 2016 & $\begin{array}{l}\text { Universidade } \\
\text { Federal do Estado } \\
\text { do Rio de Janeiro }\end{array}$ & $\begin{array}{c}\text { Deborah Silva } \\
\text { de Queiroz }\end{array}$ \\
\hline $\begin{array}{l}\text { 2. A Guerrilha do Araguaia: memória, } \\
\text { esquecimento e Ensino de História } \\
\text { na região do conflito }\end{array}$ & 2016 & $\begin{array}{l}\text { Universidade } \\
\text { Federal de } \\
\text { Tocantins }\end{array}$ & $\begin{array}{l}\text { José } \\
\text { Humberto } \\
\text { Gomes } \\
\text { Barbosa }\end{array}$ \\
\hline $\begin{array}{l}\text { 3. Imprensa64.pro.br: materiais } \\
\text { didáticos sobre o golpe de estado de } \\
1964 \text { por meio da imprensa brasileira }\end{array}$ & 2016 & $\begin{array}{c}\text { Universidade } \\
\text { Estadual de Santa } \\
\text { Catarina }\end{array}$ & $\begin{array}{c}\text { Juliana } \\
\text { Hachmann }\end{array}$ \\
\hline $\begin{array}{l}\text { 4. Ensino de história: o olhar dos e } \\
\text { das estudantes do nono ano, da } \\
\text { EEEM Lilia Neves (Rio Grande, RS) } \\
\text { sobre a ditadura civil militar }\end{array}$ & 2016 & $\begin{array}{l}\text { Universidade } \\
\text { Federal do Rio } \\
\text { Grande }\end{array}$ & $\begin{array}{l}\text { Júlio Cezar } \\
\text { Gonçalves } \\
\text { Sosa }\end{array}$ \\
\hline $\begin{array}{l}\text { 5. As memórias dos jovens sobre a } \\
\text { ditadura civil-militar e a função social } \\
\text { do historiador/ professor }\end{array}$ & 2017 & $\begin{array}{l}\text { Universidade } \\
\text { Federal do Rio de } \\
\text { Janeiro }\end{array}$ & $\begin{array}{c}\text { Licia Gomes } \\
\text { Quinan }\end{array}$ \\
\hline $\begin{array}{l}\text { 6. Práticas teatrais no Ensino de } \\
\text { História: contribuições de Augusto } \\
\text { Boal e Paulo Freire }\end{array}$ & 2017 & $\begin{array}{l}\text { Universidade } \\
\text { Federal de Santa } \\
\text { Catarina }\end{array}$ & $\begin{array}{l}\text { Cleyton } \\
\text { Machado }\end{array}$ \\
\hline $\begin{array}{l}\text { 7. Arte de guerrilha e Ensino de } \\
\text { História: abordagem didática da } \\
\text { resistência à ditadura civil-militar no } \\
\text { Brasil a partir das obras de Cildo } \\
\text { Meireles }\end{array}$ & 2018 & $\begin{array}{l}\text { Universidade } \\
\text { Federal do } \\
\text { Paraná }\end{array}$ & $\begin{array}{c}\text { Izabella } \\
\text { Gomes Lopes } \\
\text { Bertoni }\end{array}$ \\
\hline $\begin{array}{l}\text { 8. Revisionismo, memória e ensino } \\
\text { de história da ditadura civil-militar - } \\
\text { por uma prática politizante }\end{array}$ & 2018 & $\begin{array}{l}\text { Universidade } \\
\text { Estadual de } \\
\text { Campinas }\end{array}$ & $\begin{array}{c}\text { Elton Rigotto } \\
\text { Genari }\end{array}$ \\
\hline $\begin{array}{l}\text { 9. Ditadura militar brasileira: } \\
\text { memória e ensino em tempos de } \\
\text { redemocratização }\end{array}$ & 2018 & $\begin{array}{l}\text { Universidade } \\
\text { Estadual de Mato } \\
\text { Grosso do Sul }\end{array}$ & $\begin{array}{l}\text { Carlos } \\
\text { Monteiro } \\
\text { Alves }\end{array}$ \\
\hline
\end{tabular}




\begin{tabular}{|c|c|c|c|}
\hline $\begin{array}{l}\text { 10. Para não esquecer: ensino de } \\
\text { História e Empatia Histórica a partir } \\
\text { da escrita de biografias de } \\
\text { desaparecidos políticos da ditadura } \\
\text { civil-militar brasileira }\end{array}$ & 2018 & $\begin{array}{l}\text { Universidade } \\
\text { Federal do Rio } \\
\text { Grande do Sul }\end{array}$ & $\begin{array}{l}\text { Fernando de } \\
\text { Lima Nunes }\end{array}$ \\
\hline $\begin{array}{l}\text { 11. Repressão e resistência na } \\
\text { ditadura civil-militar: construção de } \\
\text { site temático para o ensino de } \\
\text { história local (Curitiba - PR) }\end{array}$ & 2018 & $\begin{array}{l}\text { Universidade } \\
\text { Federal do Paraná }\end{array}$ & $\begin{array}{l}\text { Luiz Gabriel } \\
\text { da Silva }\end{array}$ \\
\hline $\begin{array}{l}\text { 12. Tocando na ferida: gênero e } \\
\text { ditadura no ensino de história através } \\
\text { da análise de testemunhos }\end{array}$ & 2018 & $\begin{array}{l}\text { Universidade } \\
\text { Federal do Rio } \\
\text { Grande do Sul }\end{array}$ & $\begin{array}{l}\text { Isadora } \\
\text { Ritterbusch } \\
\text { Librenza }\end{array}$ \\
\hline $\begin{array}{l}\text { 13. Ensino de história e passados } \\
\text { sensíveis: história e memória da } \\
\text { ditadura militar nos livros didáticos } \\
\text { do Brasil e da Argentina }\end{array}$ & 2018 & $\begin{array}{l}\text { Universidade } \\
\text { Regional do Cariri }\end{array}$ & $\begin{array}{l}\text { Ellen Natucha } \\
\text { Pedroza } \\
\text { Bezerra }\end{array}$ \\
\hline $\begin{array}{l}\text { 14. Práticas políticas repressivas do } \\
\text { século XX e consciência histórica: um } \\
\text { propositivo didático das aulas de } \\
\text { história no Colégio Santa Cruz - } \\
\text { Araguaína - TO }\end{array}$ & 2018 & $\begin{array}{l}\text { Universidade } \\
\text { Federal de } \\
\text { Tocantins }\end{array}$ & $\begin{array}{l}\text { Kamila Soares } \\
\text { de Araujo } \\
\text { Coimbra }\end{array}$ \\
\hline $\begin{array}{l}\text { 15. Tempo de lembrar: memórias da } \\
\text { ditadura e ensino de História do } \\
\text { Amapá }\end{array}$ & 2018 & $\begin{array}{c}\text { Universidade } \\
\text { Federal do Amapá }\end{array}$ & $\begin{array}{l}\text { Danilo Mateus } \\
\text { da Silva } \\
\text { Pacheco }\end{array}$ \\
\hline $\begin{array}{l}\text { 16. Formação em direitos humanos } \\
\text { no ensino de História: diálogos entre } \\
\text { a escola e uma sociedade polarizada }\end{array}$ & 2019 & $\begin{array}{l}\text { Universidade } \\
\text { Federal do Rio } \\
\text { Grande do Norte }\end{array}$ & $\begin{array}{c}\text { Osvaldo } \\
\text { Santos Falcão }\end{array}$ \\
\hline $\begin{array}{l}\text { 17. História, narrativa gráfica e a } \\
\text { ditadura militar em Belém: presente, } \\
\text { passado e futuro pela ótica da arte } \\
\text { sequencial }\end{array}$ & 2019 & $\begin{array}{l}\text { Universidade } \\
\text { Federal do Pará }\end{array}$ & $\begin{array}{l}\text { Plínio Sá de } \\
\text { Araujo }\end{array}$ \\
\hline $\begin{array}{l}\text { 18. Trilhas da ditadura civil-militar na } \\
\text { cidade do Rio de Janeiro: roteiro para } \\
\text { Educação em Direitos Humanos }\end{array}$ & 2019 & $\begin{array}{l}\text { Universidade } \\
\text { Estadual do Rio de } \\
\text { Janeiro }\end{array}$ & $\begin{array}{c}\text { Vinícius Ávila } \\
\text { da Silva }\end{array}$ \\
\hline
\end{tabular}

Fonte: Plataforma Sucupira e Portal eduCapes.

O quadro acima indica que as dissertações que tiveram a ditadura civilmilitar como tema foram desenvolvidas em 15 das 28 instituições associadas ao ProfHistória entre 2014 e 2019¹. Distribuídas por todas as regiões do Brasil, tiveram maior presença na região Sul, que contava com oito universidades integrantes do

\footnotetext{
A Universidade Federal do Rio Grande integrou a rede do ProfHistória na turma de 2014, tendo se desligado a partir da turma de 2016. Por isso, esteve entre as 12 instituições associadas no momento da criação do curso, mas ausente das 27 universidades que participaram da segunda turma, em 2016. Daí o número total de 28 instituições associadas quando consideramos os alunos que entraram em 2014 e 2016.
} 
ProfHistória e sete trabalhos defendidos, e na região Norte, com três instituições associadas e quatro dissertações finalizadas - o mesmo número de trabalhos da região Sudeste, que contabilizava então oito universidades associadas.

Após esse levantamento inicial, o texto das dissertações foi acessado através do Portal eduCapes. Foi realizada a leitura do resumo, sumário, introdução e a dimensão propositiva de cada um dos trabalhos, investigando as razões e justificativas expressas pelos professores para eleger o tema da ditadura civil-militar como objeto de sua pesquisa e elaborar suas propostas didáticas, em diálogo com as demandas do contexto da década de 2010 e as finalidades da história escolar. Não procedemos a uma análise quantitativa dos principais elementos presentes nas dissertações; antes, buscamos identificar e analisar as diferentes perspectivas indicadas pelos professores acerca do ensino da ditadura civil-militar entre 2014 e 2019.

No tempo presente: as disputas de memória e o ensino de história

Um olhar imediato sobre os títulos das dissertações já indica a presença do tema da memória, em diálogo com outros aspectos específicos - resistência, história local, juventude, revisionismo e livros didáticos. Nos textos, essa presença se traduziu em relatos frequentes de embate entre diferentes memórias sobre a ditadura civil-militar na sala de aula, incluindo a defesa dos anos ditatoriais como um tempo positivo de crescimento econômico, segurança e ausência de corrupção. Também foram relatadas situações em que estudantes minimizaram ou justificaram a violência praticada pelo Estado ditatorial ou declararam sua inexistência na região ou nos espaços sociais onde vivem.

Em meio a esse cenário, começaram a emergir distintos interrogantes científicos e sociais para os pesquisadores, que incluíram a reflexão "sobre métodos e práticas que garantissem aos estudantes o desenvolvimento de habilidades e conhecimentos necessários para a compreensão crítica da multiplicidade de interpretações e representações feitas do período" (GENARI, 2018, p. 13) e, também, "sobre o ensino da história da Ditadura Civil-Militar numa abordagem de defesa e garantia dos Direitos Humanos" (NUNES, 2018, p. 14). Para a professora Deborah Queiroz, não era possível “aceitar e conviver, passivamente, 
com as indagações dos alunos sobre o período da ditadura militar, feitas sob o manto da desinformação" (QUEIROZ, 2016, p. 109). Assim, entre a surpresa e o desconforto, os professores se voltaram para investigar a potencialidade do ensino da História para problematizar e transformar essas memórias.

A compreensão dos trajetos de pesquisa e dos resultados obtidos demanda examinar como seus autores se relacionam com a história das memórias sobre a ditadura no Brasil, forjada nas lutas entre diversos grupos que interagem em contextos políticos específicos (JELIN, 2014). Esse processo se constitui pelas formas de lembrar o passado ditatorial elaboradas e divulgadas por diferentes sujeitos ao longo do tempo, que se fazem presentes na arena pública e moldam um repertório socialmente compartilhado; algumas formas de lembrar alcançam maior ou menor força em distintos momentos, configurando uma história das memórias sobre a ditadura que se mantém aberta a alterações em novos contextos e a partir da ação interessada dos sujeitos - como os professores-mestres do ProfHistória.

Nessa perspectiva, é relevante sublinhar que as dissertações aqui analisadas se desenvolveram entre os anos de 2014 e 2019, marcados pela crise do governo do Partido dos Trabalhadores, pela ocorrência de manifestações públicas massivas, pelo processo de impeachment da ex-presidente Dilma Rousseff e pela ascensão e eleição para presidente da República de um político de extrema-direita, publicamente defensor da ditadura. No período, também se verificou a proliferação da produção e divulgação de narrativas sobre a ditadura nas redes sociais e na internet e a finalização dos trabalhos das comissões da verdade no país.

Historiadores que analisam as memórias sobre a ditadura convergem na afirmação das diferentes inflexões produzidas nesse contexto. Marcos Napolitano (2020) identificou três fases da memória sobre a ditadura militar entre os anos de 1964 e 2014, com uma ruptura importante a partir desse último. Na primeira fase, compreendida entre 1964 e 1974, teriam emergido as "experiências matrizes" das memórias, seguida pela fase do "enquadramento narrativo" dessas experiências entre 1974 e 1994, na qual se tornou hegemônica uma memória de viés liberal crítica à ditadura e pautada no isolamento político dos militares e na 
recusa ao encaminhamento das questões referentes à verdade, memória, reparação e justiça. Para Napolitano, essa memória esteve na base dos acordos de construção da chamada Nova República², se desdobrando em medidas direcionadas ao esquecimento da violência ditatorial e na não punição dos agentes do Estado que violaram os direitos humanos. A última fase seria a das “políticas de memória”, entre 1995 e 2014, quando houve um avanço no estabelecimento da verdade e na reparação às vítimas da ditadura, cujas memórias ganharam maior divulgação - ainda que sem a perspectiva da justiça pela confirmação da interpretação da Lei de Anistia pelo Supremo Tribunal Federal, em 2010. Para Napolitano, os aportes críticos produzidos por essas políticas de memória desafiaram os pilares da memória hegemônica e mobilizaram grupos de extrema-direita, formado por civis e militares, a defender publicamente uma narrativa positiva da ditadura.

Entre as políticas de memória estatais implementadas, a Comissão Nacional da Verdade (CNV), de 2012 a 2014, merece destaque. Segundo Pereira (2015), a ação da extrema-direita verificada a partir de meados da década de 2010 se relacionou diretamente com os trabalhos desenvolvidos pela CNV, cujas audiências públicas, oitivas e relatório final desestabilizaram a indistinção entre algoz e vítima - presente na interpretação da ideia de crimes conexos na Lei de Anistia - ao apontar os nomes dos militares responsáveis pelas violações dos direitos humanos, inclusive dos generais que ocuparam a presidência da república; afirmar as práticas da tortura, de assassinato e de desaparecimento de corpos como políticas de Estado e indicar a revisão da Lei da Anistia. Em direção semelhante, Caroline Bauer (2017) ressaltou a proliferação dos discursos negacionistas e revisionistas conforme a CNV avançou em suas investigações. Advindas de setores militares, essas narrativas sobre o passado ditatorial justificavam o golpe de Estado de 1964 como uma forma de evitar a implantação do comunismo e a tortura como excessos praticados por indivíduos, reforçando publicamente memórias elaboradas décadas atrás.

\footnotetext{
${ }^{2}$ Denominação dada ao período iniciado em 1985 com a eleição indireta para a presidência da República da chapa formada por dois políticos civis, Tancredo Neves e José Sarney. Findavase, assim, o período inaugurado em 1964, no qual a presidência foi ocupada por oficiais militares, sobretudo generais do Exército.
} 
Nesse contexto, aponta Napolitano,

O ano de 2015 marcou um momento importante de afirmação pública do revisionismo ideológico, com a tomada das ruas pela extrema-direita saudosa do regime militar. A conjugação da memória ressentida de grupos militares com os nostálgicos civis da ditadura ganhou as ruas e a esfera pública. [...] nesse momento, os tabus e pudores dos nostálgicos da ditadura foram rompidos, em nome da luta contra a corrupção e as esquerdas no poder. com o acirramento da crise política que culminou no impeachment de Dilma Rousseff, a esfera pública se viu tomada pelo "retorno do recalcado" da memória da extrema direita, e por negacionismos e revisionismos de natureza puramente ideológica em relação à ditadura.

[...] paulatinamente, outras narrativas começaram a romper os tabus e silêncios autoimpostos pelos perpetradores e seus herdeiros e simpatizantes, culminando na reivindicação de uma "outra narrativa histórica", frequentemente às expensas da verdade histórica, na campanha eleitoral de 2018. (NAPOLITANO, 2020, p. 38-41)

As redes sociais e a internet constituíram um espaço crucial para a ação da extrema-direita e suas narrativas negacionistas acerca do passado ditatorial, propiciando a formação de uma "comunidade de memória em rede" (PEREIRA, 2015). Fernando Nicolazzi (2019) analisou produções escritas e audiovisuais da empresa gaúcha Brasil Paralelo, um agente importante dessa comunidade, identificando seus mecanismos de construção argumentativa sobre a ditadura. Um aspecto primordial da atuação pública da empresa é sua autoafirmação como independente, apartidária e imparcial, comprometida com uma análise "puramente historiográfica”, ao contrário do que ocorreria na produção universitária, que seria ideologicamente influenciada pela esquerda e, portanto, deslegitimada como interlocutora.

Três tópicos destacados por Nicolazzi, da obra Entre mitos e verdades. $A$ história do regime militar, publicada como e-book gratuito em 2018, pela Brasil Paralelo, indicam os eixos da narrativa pretendida: a afirmação da existência de uma ameaça comunista no país como justificativa para a deposição de João Goulart em "defesa da democracia"; a negação do caráter de golpe de Estado para a ação civil-militar de 1964 em razão desta ter sido apoiada por parte da sociedade; e o estabelecimento de um nexo de causalidade entre "ação" dos grupos de luta armada e "reação" repressiva estatal, reatualizando a proposição 
de uma "guerra entre dois lados". A essa narrativa que se remete às já existentes memórias defendidas por setores militares e de extrema-direita, Marcos Napolitano adicionou um último elemento referente à busca de desqualificação da memória das vítimas da violência de Estado, cujos testemunhos foram publicamente colocados em dúvida, e à tentativa de sua criminalização (NAPOLITANO, 2020).

Como sinalizado acima, essa articulação discursiva da extrema-direita acusa insistentemente a produção historiográfica e o ensino de História de divulgarem interpretações distorcidas da história nacional em razão de supostas influências ideológicas de esquerda. No caso dos professores da educação básica, somou-se a isso a atuação do Movimento Escola sem Partido (MESP) ${ }^{3}$, cujas publicações online intentam reforçar a ideia de que os docentes ensinariam "um lado da história” (MOURA; SALLES, 2018).

Assim, no tempo em que realizaram suas pesquisas, os mestres do ProfHistória vivenciaram as inflexões na história das memórias sobre a ditadura oriundas dos trabalhos das comissões da verdade, que desestabilizaram a concepção hegemônica caracterizada por Napolitano, ao estabelecer novos espaços para a voz das pessoas afetadas pela violência ditatorial, e da ação dos grupos de extrema-direita. Foram interpelados continuamente por estudantes, famílias, políticos e gestores de colégio e das secretarias de educação, enfrentando o desafio de lidar com a disseminação de discursos de defesa ou negação da ditadura nas redes sociais, além dos ataques à legitimidade social de seu conhecimento e à sua autoridade como parte de uma comunidade científica.

Como resposta a essas experiências, os professores construíram diferentes aproximações com a questão das memórias sobre a ditadura. Uma delas, presente em vários trabalhos, voltou-se para a elaboração de atividades que tiveram como base tratar as diferentes memórias existentes sobre o

\footnotetext{
3 O Movimento Escola sem Partido (MESP) foi criado no ano de 2004 pelo advogado católico Miguel Nagib, ganhando maior notoriedade a partir da década de 2010. Aliando-se, ao longo do tempo, a movimentos políticos e cristãos conservadores, o MESP desenvolveu uma atuação pública baseada em acusações de "doutrinação" feitas a professores e se aproximou de parlamentares de extrema-direita na elaboração de projetos de lei que visam estabelecer mecanismos de controle, vigilância e criminalização de docentes. Sobre as manifestações do MESP referentes ao tema da história da ditadura, ver FARIAS; OLIVEIRA, 2020.
} 
passado ditatorial e seus enfrentamentos na arena pública. É o caso do trabalho de Queiroz (2016), no qual foram selecionados depoimentos de vítimas da ditadura e de militares, produzidos sobretudo pela CNV, ao lado da proposta de uma metodologia de análise de filmes a partir do documentário intitulado "15 filhos", com testemunhos de filhos e filhas de pessoas torturadas, mortas ou desaparecidas entre 1969 e 1975. Essa mesma perspectiva foi encontrada no trabalho de Alves (2018), que mobilizou depoimentos de vítimas da violência ditatorial e de militares, oriundos da CNV e de obras que registraram as memórias do último grupo. Com o mesmo objetivo de colocar em debate distintas memórias sobre a ditadura, Araújo (2019) construiu uma estratégia distinta baseada na arte gráfica. Em sua dissertação, foram criadas quatro histórias em quadrinhos que se passaram na cidade de Belém. A primeira delas, de caráter ficcional e intitulada $A$ bipolarização política entre esquerda e direita, contou a trajetória de dois irmãos que ocuparam posições opostas no processo político que culminou no impeachment da ex-presidente Dilma Rousseff, entre 2014 e 2016. Tendo o presente como ponto inicial da proposta didática, as três histórias seguintes, criadas a partir da consulta a trabalhos historiográficos e acervos de história oral relativos à história do Pará, enfocaram eventos anteriores e posteriores a 1964 envolvendo forças da esquerda e da direita, episódios de confronto e violência estatal.

Na pesquisa de Silva, foram disponibilizados em um site ${ }^{4}$ documentos históricos relativos a indivíduos perseguidos pelo Estado, a agentes da repressão e a imprensa local do Paraná, apostando que seu uso por estudantes e professores colocaria em diálogo diferentes experiências e permitiria discutir "a multiplicidade de agentes imbricados no processo de construção da realidade histórica" (SILVA, 2018, p. 123). Em direção semelhante, Barbosa (2016) propôs a utilização de materiais sobre a Guerrilha do Araguaia abrangendo guerrilheiros, militares, indígenas e camponeses, jogando luz na diferença de perspectivas e, também, debatendo o processo de silenciamento das memórias da população local, que, segundo o autor, foram suplantadas pelo protagonismo dado a militantes da luta armada e repressores.

${ }^{4} \mathrm{O}$ site está disponível em https://ditaduraemcuritiba.com.br/. Acesso em 31 de julho de 2021. 
A dissertação de Hachmann (2016) não tratou diretamente da questão relativa às memórias sobre a ditadura; ela desenvolveu um conjunto de atividades que objetivou aprimorar a capacidade dos estudantes de se apropriar criticamente de fontes de informação. Partindo da proposta Reading Like a Historian $^{5}$, a autora selecionou materiais da imprensa que apresentavam perfis ideológicos distintos e, por isso, versões conflitantes sobre o governo de João Goulart e o golpe de 1964, construindo um percurso de análise próximo ao método de pesquisa histórica baseado no cotejamento de diferentes documentos para o exercício de construção de argumentação. Justificando sua escolha, Hachmann enfatizou a importância do desenvolvimento da leitura crítica das produções da mídia e a atualidade dos temas históricos escolhidos, o que possibilitaria, através do ensino de história, discutir e problematizar a "batalha de memórias em torno do golpe de Estado" de 1964, familiar a seus estudantes (HACHMANN, 2016, p. 90).

A aposta na capacidade do ensino de História de desenvolver ferramentas críticas para a apropriação de informações e de usos do passado também orientou o trabalho de Genari (2018), no qual ele defendeu a aula de História como um espaço para tratar as disputas de memórias sobre a ditadura em um contexto marcado pelo que denominou de revisionismo conservador, que encontrou na internet um meio poderoso para se disseminar. Sua proposição didática mobilizou testemunhos dados por filhos e filhas de vítimas da ditadura à Comissão da Verdade do Estado de São Paulo - Rubens Paiva, reunidos na publicação Infância Roubada, em propostas didáticas integradas por diferentes materiais.

Como afirmado anteriormente, outro impulso que aproximou os professores do tema da história da ditadura civil-militar como objeto de pesquisa foi a força adquirida por memórias positivas ou de justificação da violência ditatorial entre os estudantes. Foi o caso de Falcão que, numa aula que incluía informações sobre a repressão praticada pelos agentes da ditadura, ouviu de um de seus alunos: "Eles mataram foi pouco". A declaração causou espanto em Falcão, que registrou em sua dissertação: “Foi então que, definitivamente, percebi

\footnotetext{
${ }^{5}$ Desenvolvida pelo Stanford History Education Group, essa metodologia pode ser encontrada em https://sheg.stanford.edu/history-lessons. Acesso em 31 de julho de 2021.
} 
a urgência de debater o tema [dos direitos humanos] em sala de aula" (FALCÃO, 2019, p. 11). Na mesma perspectiva, o trajeto da pesquisa de Quinan (2016) foi traçado a partir do contato com posições de seus alunos que relativizaram a tortura e afirmavam a ausência de corrupção na ditadura civil-militar, o que gerou um questionamento pessoal acerca das funções sociais do historiador/professor de História diante do fortalecimento dessas memórias.

A reação a essas experiências derivou na criação de propostas voltadas para intervir e transformar as memórias sociais sobre a ditadura e as concepções dos estudantes sobre direitos humanos, explicitando a intenção dos professores de atuar nas disputas acerca dos significados do passado ditatorial no presente. Essas propostas também veicularam a perspectiva de que o trabalho didático com a violência estatal e a desigualdade social, sob a ditadura, pode concorrer para a construção de um novo olhar dos estudantes sobre essas questões no seu próprio tempo. Nas palavras dos próprios autores, o ensino da história da ditadura na educação básica seria uma "ferramenta privilegiada de desconstrução dos valores antidemocráticos e de desrespeito aos direitos humanos" (QUINAN, 2017, p. 14), além de um mecanismo de estímulo ao "desenvolvimento de uma memória que oriente ações pautadas em uma irredutível defesa dos Direitos Humanos" (GENARI, 2018, p. 10).

Um exemplo dessa aproximação com a questão da memória é a pesquisa de Falcão (2019), que partiu de uma análise dos direitos humanos no âmbito da legislação e da educação. Posteriormente, foram realizadas entrevistas com estudantes para identificar suas visões sobre tortura e direitos humanos, seguida de uma atividade com um membro da Comissão Estadual da Verdade da Paraíba sobre as violências cometidas pelo agentes da repressão no Estado e, por fim, uma nova entrevista com estudantes que participaram da atividade - essas últimas três etapas geraram um documentário disponível no YouTube ${ }^{6}$. Quinan (2017) organizou um grupo focal para identificar de maneira mais precisa as memórias dos jovens sobre a ditadura e suas fontes de informação, o que originou a produção de um caderno de atividades com documentos sobre o tema dos direitos humanos e aspectos da economia e sociedade brasileira nas

${ }^{6} \mathrm{O}$ documentário pode ser visto em https://www.youtube.com/watch?v=j-EEfKcCX3o. Acesso em 27 de julho de 2021. 
décadas de 1960 a 1980 que problematizavam as ideias de crescimento econômico e desenvolvimento.

Na mesma direção, Bezerra (2018) analisou as relações entre memória e esquecimento nos livros didáticos em perspectiva comparada - Brasil e Argentina -, construindo um blog educativo no qual disponibilizou textos, testemunhos, fotografias, vídeos, sugestão de filmes e músicas, identificação de lugares de memória, atividades e materiais produzidos pelas comissões da verdade, em diálogo intenso com a historiografia sobre as ditaduras. $\mathrm{Na}$ apresentação do $b \log ^{7}$, a autora afirmou que seu estudo tratou de

uma análise acerca da memória e História das ditaduras militares no Brasil e na Argentina. Essa opção ocorreu, principalmente, devido à circulação de ideias conservadoras e comentários infundados sobre o assunto nos últimos tempos, nas mídias, nas ruas, corredores das escolas e salas de aulas.

Portanto, dada a profusão dessas ideias em cena pública que chegam a desrespeitar a memória de vítimas da repressão, optamos por realizar um estudo comparativo das narrativas nos livros didáticos acerca das ditaduras militares. (BEZERRA, 2018, p. 137)

A citação de Bezerra tangencia um elemento presente em várias dissertações que nos remete ao espaço concedido às vítimas da repressão ditatorial e à intenção de valorizar suas experiências históricas e subjetividades, manifestando diferentes diálogos com a ideia de "dever de memória". Esse elemento está presente tanto nos trabalhos de professores com trajetórias pessoais atravessadas pela violência ditatorial, como também nos daqueles cuja aproximação com o tema se processou através de trajetórias de pesquisas ou de convergências político-ideológicas construídas no presente. Assim, as dissertações foram dedicadas "àqueles que lutaram contra a ditadura, contra a implementação do ensino pago em Universidades públicas, que tiveram suas garantias individuais violadas, sua liberdade tolhida, sua dignidade vilipendiada. [..] vocês inspiram gerações" (SILVA, 2018, p. 3), e "a todos e todos [sic] que doaram suas vidas, alguns literalmente, na luta contra esse duro período da nossa história. Fazer com que as novas gerações conheçam esse momento é

\footnotetext{
7 O blog está disponível em http://memoriasdasditaduras.com.br/. Acesso em 27 de julho de
} 2021. 
uma obrigação nossa para com todos e todas" (SOSA, 2016, p. 4); por sua vez, uma professora definiu como a motivação principal de sua pesquisa "trazer à tona a memória daqueles que lutaram por um país no mínimo diferente do que temos hoje" (QUEIROZ, 2016, p. 109).

Em outros trabalhos, o "dever de memória" aproximou-se da questão da justiça. Nesse caminho, Nunes (2018) destacou que o ensino da história da ditadura civil-militar implica a reflexão sobre o “dever de memória” remetendose à noção de justiça proposta por Paul Ricouer, que demanda uma ação que assegura o não esquecimento das experiências de sofrimento das vítimas aliada à crítica historiográfica. Já Quinan defendeu a possibilidade de conceber o ensino da ditadura civil-militar na educação básica como um "braço da justiça de transição" (QUINAN, 2017, p. 13), no qual poderiam ser desenvolvidas práticas para concretizar os direitos à memória e à verdade e visibilizar os relatos das vítimas da violência ditatorial, estabelecendo uma espécie de reparação a essas pessoas pelo compartilhamento e reconhecimento social de suas vivências.

Do que foi exposto até aqui, é possível destacar diferentes equilíbrios entre as dimensões científica e social no ensino da história da ditadura civil-militar na educação básica. Numa primeira direção, os professores afirmaram a urgência de contemplar e de dar inteligibilidade às disputas políticas e de memória vividas no país desde meados dos anos 2010. No esforço de transformar essa urgência em práticas, ficou explícita a intencionalidade de desenvolver operações cognitivas capazes de forjar nos estudantes a habilidade de contextualizar as memórias sobre a ditadura, reconhecendo sua pluralidade e os conflitos que se instalam na sociedade. Recorrendo aos subsídios da escrita da história, os professores defenderam uma apropriação crítica das memórias e de seus meios de produção e transmissão através do uso intenso de documentos históricos cotejados com textos historiográficos e didáticos, induzindo os estudantes a explorar sua "capacidade de extrair e correlacionar informações a partir dessas evidências, concebendo uma perspectiva mais científica para o ensino de História” (CAIMI, 2015, p. 29-30).

Essa operação também propiciou aos professores reforçar a legitimidade de seu saber ao buscar diferenciar, através do uso de metodologias específicas 
da História, o conhecimento produzido na universidade e na escola das narrativas que se originam na internet e nos círculos familiares, identificados como principais fontes de memórias positivas ou negacionistas da ditadura. Nesse sentido, a interlocução entre a Teoria da História e o ensino da disciplina na educação básica, uma das matrizes centrais da formação proposta pelo ProfHistória, parece ter aprofundado nos mestrandos a análise sobre a especificidade das operações cognitivas realizadas pela História e sua potencialidade para participar e intervir nas disputas de memórias.

A questão do embate entre memórias sobre a ditadura também foi vista pelos professores como uma possibilidade de criar práticas voltadas para a discussão da diferença e do conflito como elementos constitutivos de qualquer ordem social, que repercutiriam nas atitudes dos estudantes para valorizar e fortalecer a democracia no presente. Isso vai ao encontro da expectativa dos professores de "formar alunos que possam atuar no processo histórico, combatendo, por meio do diálogo, narrativas que fazem apologias ao autoritarismo de outrora e que contribuam para uma sociedade mais tolerante e menos violenta" (PACHECO, 2018, p. 24-25, grifo nosso) e de que o conhecimento histórico escolar

pode auxiliar na formação de cidadãos politizados, que compreendam e respeitem a diversidade, seja ela contemporânea - o colega que tem uma orientação sexual, identidade de gênero, raça, religião diferente da sua - ou histórica - a forma de pensar/agir/viver em outro tempo histórico que não é o nosso e que, por isso, não pode ser menosprezado ou caricaturizado [...]. (NUNES, 2018, p. 80, grifo nosso)

Em movimento semelhante, vários professores justificaram a seleção de materiais com foco na violação dos direitos humanos praticada pelos agentes da ditadura, principalmente a tortura, como estratégia para produzir um rechaço à sua permanência no presente. Bertoni afirmou que sua intenção, ao destacar conteúdos referentes à violência e à censura em sua pesquisa, foi

acentuar esses pontos negativos para promover uma valorização do regime democrático, do respeito às liberdades individuais, coletivas e de um engajamento contra a opressão e a violência, fazendo com que esses/essas discentes refletissem sobre tais assuntos e tomassem consciência da necessidade de nos 
posicionarmos de forma contrária ao Estado autoritário e, assim, promover uma educação para a cidadania, para a defesa dos direitos humanos e para o respeito às diferenças de maneira geral. (BERTONI, 2018, p. 194, grifo nosso)

Nos excertos aqui destacados, o ensino da história da ditadura civil-militar emerge também como face do compromisso social dos docentes com a defesa do regime democrático e da cidadania. Vale apontar quais aspectos da ditadura foram especialmente enfatizados pelos professores uma vez que eles nos revelam, seguindo a provocação de Raggio, suas visões acerca da democracia, vivida ou projetada: violência/diálogo, intolerância e opressão/diversidade e diferença, tortura/liberdades individuais e coletivas e direitos humanos.

No tempo presente: estratégias docentes para os alunos de hoje

A análise dos textos e proposições didáticas registrou as inúmeras estratégias elaboradas pelos professores diante do desafio de ensinar a história da ditadura civil-militar no tempo presente, revelando o caráter criativo e produtivo das práticas docentes (GONZALEZ, 2018) e reforçando a história escolar como uma disciplina potente para a formação crítica dos estudantes; também afirmaram a si mesmos como agentes participantes nas disputas de memórias sobre a ditadura e na defesa da democracia. Outra marca distintiva desses textos, indispensável para a compreensão das criações dos professores, é a insatisfação de seus autores com o contraste entre a maneira como concebem o potencial e o valor do ensino de História nos dias atuais e o não engajamento de seus alunos nas aulas. Neste sentido, o professor Júlio Cezar Gonçalves Sosa manifestou "a inquietação de perceber o distanciamento do que é ensinado dos sujeitos que tenho a minha frente; a angústia de perceber, muitas vezes, o distanciamento deles de todo o processo" (SOSA, 2016, p. 42).

Em decorrência dessa percepção, muitas pesquisas se voltaram para a reflexão sobre como ensinar a história da ditadura civil-militar tendo como objetivo primordial criar estratégias para propiciar e estimular a participação dos estudantes na construção do conhecimento. Com esse fim, os professores selecionaram e construíram materiais, referenciais teóricos e metodologias variados. Registramos, nas proposições examinadas, o uso de filmes de ficção e 
documentários, músicas, testemunhos escritos e em vídeo, produção de zines e histórias em quadrinhos, criação de sites, análise e produção de arte plástica contemporânea, documentos escritos e imagens, práticas teatrais, debates, grupos focais, aulas de campo.

As justificativas para a escolha desses materiais destacaram a opção por linguagens audiovisuais e mídias digitais que seriam mais próximas do cotidiano dos estudantes, reforçando a intencionalidade de dialogar com as experiências juvenis; a seleção de documentos enfocando situações de violência vividas por crianças e adolescentes durante a ditadura também foi relacionada à possiblidade de produzir uma identificação etária entre alunos e os personagens históricos. Biografias e testemunhos foram meios pensados para introduzir a questão das subjetividades e estabelecer novos caminhos para o ensino. Segundo Librenza, cuja dissertação relacionou a história da ditadura a questões de gênero, o testemunho

possibilita que o "gelo" entre a história e estudante seja quebrado, na medida em que, antes de imergir em categorias e conceitos novos, os estudantes já partam da dimensão humana do ocorrido, o que também desperta dúvidas e corriqueiramente suscita questionamentos, a partir dos quais as aulas se desenrolam levando em consideração os interesses das e dos estudantes. (LIBRENZA, 2018, p. 11)

Como pontuado anteriormente, materiais produzidos pelas comissões da verdade foram utilizados em muitas dissertações para compor os textos e as proposições didáticas. Aqui, destacamos quatro apropriações com diferentes finalidades. De maneira bastante frequente, foram reproduzidos trechos de depoimentos e dados dos relatórios finais das comissões com o sentido de apresentar a "verdade" dos fatos. Os professores mobilizaram informações relativas à quantidade de pessoas mortas ou desaparecidas em decorrência da ação de agentes do Estado ditatorial, os nomes desses agentes ou partes de depoimentos deles ou de pessoas atingidas pela repressão relatando suas experiências pessoais. Nesse uso, os relatórios da CNV e das comissões estaduais assumiram um status de referência oficial para apresentar aos estudantes o que se passou durante a ditadura civil-militar. 
Essa apropriação carrega alguns riscos tais como a ausência de uma reflexão sobre o tempo em que esses órgãos foram criados, seus modos de funcionamento, as dinâmicas específicas de realização dos depoimentos e os conflitos internos e externos que, muitas vezes, influenciaram e moldaram a produção dos relatórios finais. Esses aspectos atuaram na conformação dos acervos e dos relatórios publicados e, muitas vezes, foram pouco ou nada abordados pelos professores em suas dissertações. Nesse sentido, os materiais das comissões da verdade foram retirados do momento histórico em que foram produzidos e das interlocuções que estabeleceram com seu tempo (GONZALEZ, 2011).

Em sentido distinto, alguns professores se aproximaram das comissões da verdade enquanto uma política de memória implementada pelo Estado na década de 2010, abrindo espaço para a discussão da história de criação e funcionamento das comissões, seus embates políticos e de memórias. Esse foi o caso especialmente da dissertação de Pacheco (2018), que analisou a trajetória das comissões da verdade e, principalmente, a Comissão Estadual da Verdade do Amapá, examinando de que forma os materiais originados nas oitivas por ela organizadas podem ser utilizados em sala de aula. Essa perspectiva é crucial para elaborar as possibilidades de abordagem desses materiais com os alunos, considerando as questões relativas a como eles se relacionam com a história das memórias sobre a ditadura e com o tempo presente e às características específicas dos depoimentos dados às comissões por militares, juízes, advogados e vítimas da repressão.

E se torna ainda mais importante quando observamos que as dissertações do ProfHistória propuseram um intenso uso de material de caráter testemunhal produzido por distintos órgãos e instituições - comissões da verdade, Ministério da Justiça, Ministério Público Federal, Forças Armadas. Em suas proposições didáticas, os professores selecionaram depoimentos de militares, trabalhadores, sindicalistas, estudantes, indígenas, mulheres, crianças e, de forma frequente, de militantes da luta armada, oriundos de diferentes acervos. Muitos trechos de depoimentos foram usados, em sua forma transcrita, em exercícios de método 
de análise documental cotejados com outras fontes históricas e textos historiográficos.

Parte relevante desses depoimentos teve como tema central a tortura, como já sublinhamos anteriormente, e o destaque à ação dos participantes das guerrilhas e do movimento estudantil, ainda que tenhamos identificado acima uma variedade maior de sujeitos. Esse aspecto se coaduna com o olhar mais aprofundado das comissões da verdade, sobretudo a CNV, sobre esses grupos sociais e converge com as pesquisas que apontam, nas narrativas de livros didáticos, o encadeamento do enredo sobre o período ditatorial a partir de marcos políticos nacionais, considerando a sucessão dos períodos presidenciais, e a resistência e a repressão do regime representadas na relação com a esfera cultural e as organizações de luta armada (ROCHA, 2017). Nesse sentido, as dissertações dialogaram fortemente com algumas tradições já estabelecidas na História escolar sobre esse período histórico, debruçando-se menos sobre o interrogante do que ensinar sobre a ditadura. Como aponta Kallás (2000), essa é uma marca encontrada na produção mais ampla sobre o ensino da ditadura civilmilitar na sala de aula.

A última forma de apropriação das comissões da verdade nas dissertações do ProfHistória se voltou para a elaboração de proposições com foco no âmbito local ou regional. Segundo o professor Luiz Gabriel da Silva, isso também concorreria para aproximar o estudo da História da "realidade do aluno, para que ele se perceba como sujeito histórico" (SILVA, 2018, p. 29) Além disso, e recuperando a afirmação da ênfase das narrativas didáticas sobre a ditadura civil-militar na perspectiva política e em determinados sujeitos localizados, especialmente, no eixo Rio-São Paulo, os professores do ProfHistória que atuam em estados como Paraná e Amapá relatam afirmações recorrentes dos alunos de que a ditadura não se fez presente onde vivem (SILVA, 2018; PACHECO, 2018). Por isso, os acervos e relatórios das comissões estaduais que identificaram centros de tortura, processos de violência e personagens locais foram utilizados para a problematização dessas memórias.

Na dissertação de Silva (2018), os locais ligados à repressão e à resistência, localizados na cidade de Curitiba e identificados pela Comissão Estadual da 
Verdade do Estado do Paraná, foram indicados e contextualizados em um site, assim como dois roteiros históricos. A elaboração de um roteiro histórico no centro da cidade do Rio de Janeiro, a partir das informações presentes no relatório final da Comissão da Verdade do Rio, também embasou o trabalho de Vinícius Ávila da Silva, gerando ainda um perfil na rede social Instagram pensado como "recurso digital de apoio, repositório imagético e iconográfico e coletivização das experiências do roteiro" (SILVA, 2019, p. 75)․ . Ambos intentaram, assim, estabelecer relações entre as grandes narrativas sobre a ditadura civilmilitar e as dinâmicas locais, acreditando que essa proximidade poderia estimular nos estudantes a participação nas discussões de História.

Nesse investimento para realizar o potencial da história escolar assegurando o engajamento e o protagonismo dos alunos no processo de ensino-aprendizagem, as reflexões teórico-metodológicas desenvolvidas pela Educação Histórica marcaram forte presença nas dissertações, com apropriações distintas em profundidade. Um dos postulados desse campo de pesquisa e ensino é a importância de conhecer as ideias dos estudantes sobre o tema a ser estudado, a partir das quais são elaboradas ações de pesquisa e práticas capazes de desestabilizá-las e modificá-las (BARCA, 2012). Orientandose por essa metodologia, muitas pesquisas estabeleceram como ação inicial a elaboração de questionários direcionados aos estudantes identificando suas ideias sobre a ditadura militar.

As atividades seguintes englobaram exercícios com documentos históricos e historiográficos, exposições dialogadas sobre algum conteúdo específico e produções dos alunos que buscaram problematizar as ideias iniciais. Nessa etapa, alguns pesquisadores construíram situações de aprendizagem centradas na experimentação do método historiográfico pelos estudantes, sublinhando uma finalidade central para a história escolar, atribuída pelos autores da Educação Histórica, de forjar a competência relativa à compreensão e apropriação da epistemologia da disciplina. Em algumas dissertações, foi aplicado um questionário final como forma de avaliar mudanças na consciência

${ }^{8}$ O perfil no Instagram é https://www.instagram.com/trilhasdaditadura.cidaderio/?hl=pt. Acesso em 2 de agosto de 2021. 
histórica dos estudantes, na esteira dos aportes de Jörn Hüsen incorporados pelos pesquisadores da Educação Histórico (BARCA, 2012).

O destaque alcançado pela Educação Histórica nas dissertações do ProfHistória vai ao encontro da importância que ela vem alcançando no campo da pesquisa em ensino de História, já identificada em estudos recentes (CAIMI, 2015; GONÇALVES; MONTEIRO, 2017). Por outro lado, suas proposições ofereceram aos professores aportes precisos para a incorporação e valorização dos saberes dos estudantes no processo de ensino-aprendizagem, assim como reverberam as expectativas nutridas a respeito das potencialidades do ensino de História: a interação entre conhecimento sobre o passado, identidade e ação do sujeito no presente e no futuro e a possibilidade de intervenção da História escolar nessa operação a partir da especificidade epistemológica da disciplina. No que concerne ao ensino da história da ditadura civil-militar situado no tempo intenso das disputas sobre o passado, essa perspectiva teórica abriu espaço para a expressão das memórias que circulam na sociedade e para a ação docente ancorada na metodologia histórica que, apostam os professores, permite modificar as ideias advindas de discursos autoritários e aprofundar a postura crítica dos estudantes; ao fim, reafirma-se o status científico e a importância social do professor de história em meio às contestações atuais.

\section{Professores de História e projetos para o futuro}

Os professores autores das dissertações do ProfHistória escreveram seus textos e proposições didáticas expressando saberes profissionais, conhecimentos acadêmicos e o movimento do mundo, em conjunto com o que consideraram que seus alunos precisam e podem realizar. Os trabalhos aqui analisados indicaram a busca por estratégias para lidar com os embates entre diferentes narrativas acerca da ditadura civil-militar, no contexto de uma sociedade atravessada pela polarização e pela ascensão da extrema-direita na qual os professores de História repensam e recriam seus espaços de atuação e funções. Subjacente a esse esforço, os professores conferem à História escolar a tarefa de defender e valorizar a democracia, a cidadania e os direitos humanos. Essa responsabilidade atravessou as dissertações, nas quais a escolha do tema 
da ditadura civil-militar e a elaboração da dimensão propositiva buscaram construir com os alunos conhecimentos históricos sobre democracia, ditadura, direitos humanos e suas violações, numa perspectiva de conhecimento do passado-reflexão sobre o presente-engajamento como sujeito histórico na transformação.

O destaque conferido pelos professores às experiências da tortura nas suas reflexões nos permite uma aproximação com suas concepções de direitos humanos e democracia, aqui vinculadas a seus aspectos políticos e civis. Num país como o Brasil, no qual as violências praticadas por agentes do Estado são recorrentes e incidem principalmente sobre os setores mais pobres e as populações negras, não é de estranhar a opção feita pelos docentes por materiais que enfocam as práticas de tortura como mecanismo para relacionar passado e presente e desenvolver discussões voltadas para o fortalecimento dos direitos civis. Todavia, é necessário ressaltar que o contato de estudantes com relatos de violência não garante automaticamente a condenação a essa prática, o que demanda uma reflexão particular sobre como tais documentos devem e podem ser trabalhados no ensino de História, considerando a sensibilidade de alunos e das pessoas cujas experiências de sofrimento são compartilhadas. No caso brasileiro, há ainda que se cuidar para não incorrer num anacronismo que impeça a identificação das diferenças temporais entre passado e presente (SILVA, 2017) - nesse caso, entre a ditadura que se estabeleceu no país entre 1964 e o regime democrático implantado a partir de 1985 -, o que ameaça o deslocamento temporal próprio da História e, também, enfraquece a criação de formas de ação transformadoras.

Por outo lado, a ênfase na construção de espaços para participação e produção dos estudantes e na exploração dos métodos de escrita da História em sala de aula podem carregar novos sentidos para a democracia - seja pela crítica à autoridade tradicional do professor, detentor do saber, e pela defesa de uma posição deste como mediador na produção do conhecimento em conjunto com as experiências e saberes dos alunos, ou pela aposta de que a vida em democracia implica compreender criticamente os usos do passado e os conflitos 
deles decorrentes, sendo capaz de rejeitar narrativas baseadas em argumentações frágeis ou falsificadoras que atacam a dignidade humana.

Como contribuição final, é relevante chamar a atenção para a rica pesquisa desenvolvida nas universidades e pelas próprias comissões da verdade, que ampliaram bastante as dimensões do controle e da violência ditatoriais registrando as experiências vividas por indígenas, populações negras, sujeitos LGBTQIA+, camponeses, moradores das favelas, mulheres e crianças, entre outros. Essa produção tem configurado um cenário bem mais diversificado das violações aos direitos humanos pela ditadura que pode gerar novos temas de debate com os alunos em diálogo com suas vivências e contextos particulares. Assim, ao lado da investigação de como ensinar a história da ditadura civil-militar, devemos refletir também sobre o que ensinar a respeito desse período.

\section{Referências}

ALMEIDA, Leandro Rosetti de. Museu da lembrança: história ensinada, narratividade e memória. 161 f. 2016. Dissertação (Mestrado Profissional em Rede Nacional PROFHISTORIA) - Faculdade de Formação de Professores, Universidade do Estado do Rio de Janeiro, São Gonçalo, 2016.

ALVES, Carlos Monteiro. Ditadura militar brasileira: memória e ensino em tempos de redemocratização. 39 f. 2018. Dissertação (Mestrado Profissional em Rede Nacional PROFHISTORIA) - Unidade Universitária de Amambai, Universidade Estadual de Mato Grosso do Sul, Amambai, 2018.

BARBOSA, JOSÉ HUMBERTO GOMES. A Guerrilha do Araguaia: memória, esquecimento e ensino de história na região do conflito. 156 f. 2016. Dissertação (Mestrado Profissional em Rede Nacional PROFHISTORIA) - Campus Universitário de Araguaína, Universidade Federal do Tocantins, Araguaína, 2016.

BARCA, Isabel. Ideias chave para a educação histórica: uma busca de (inter)identidades. História Revista, Goiânia, v. 17, n. 1, p. 37-51, jan./jun. 2012.

BAUER, Caroline Silveira. Como será o passado?: história, historiadores e a comissão nacional da verdade. Jundiaí: Paco, 2017.

BERTONI, Izabella Gomes Lopes. Arte de guerrilha e ensino de história: abordagem didática da resistência à ditadura civil-militar no Brasil a partir das obras de Cildo Meireles. 248 f. 2018. Dissertação (Mestrado Profissional em Rede Nacional PROFHISTORIA) - Setor de Ciências Humanas, Universidade Federal do Paraná, Curitiba, 2018. 
BEZERRA, Ellen Natucha Pedroza. Ensino de história e passados sensíveis: história e memória da ditadura militar nos livros didáticos do Brasil e da Argentina. 202 f. 2018. Dissertação (Mestrado Profissional em Rede Nacional PROFHISTORIA) - Centro de Humanidades, Universidade Regional do Cariri, Crato, 2018.

CAIMI, Flávia Eloisa. Investigando os caminhos recentes da história escolar: tendências e perspectivas de ensino e pesquisa. ROCHA, Helenice et al. (org.). O ensino de história em questão: cultura histórica, usos do passado. Rio de Janeiro: FGV Editora, 2015. p. 17-36.

CARNOVALE, Vera; LARRAMENDY, Alina. Enseñar la historia reciente en la escuela: problemas y aportes para su abordaje. In: CIENCIAS SOCIALES EN LA ESCUELA: criterios y propuestas para la enseñanza. Buenos Aires: Aique, 2010. p. 237-265.

FALCÃO, Osvaldo Santos. Formação em direitos humanos no ensino de história: diálogos entre a escola e uma sociedade polarizada. 96 f. 2019. Dissertação (Mestrado Profissional em Rede Nacional PROFHISTORIA) - Centro de Ciências Humanas, Letras e Artes, Universidade Federal do Rio Grande do Norte, Natal, 2019.

FARIAS, José Aírton de; OLIVEIRA, Danielle Rodrigues de. Ensino de ditadura civil-militar em tempos de "Escola Sem Partido". Revista Eletrônica de Educação, São Carlos, v. 14, p. 1-20, jan./dez. 2020.

GENARI, Elton Rigotto. Revisionismo, memória e ensino de história da ditadura civil-militar - por uma prática politizante. 138 f. 2018. Dissertação (Mestrado Profissional em Rede Nacional PROFHISTORIA) - Instituto de Filosofia e Ciências Humanas, Universidade Estadual de Campinas, Campinas, 2018.

GONÇALVES, Nadia Gaiofatto; MONTEIRO, Ana Maria Ferreira da Costa. Saberes e práticas docentes e ensino de história: temas, conceitos e referenciais (19702014). Educação em Revista, Belo Horizonte, n. 33, p. 1-26, 2017.

GONZÁLEZ, Maria Paula. La última dictadura argentina en el aula: entre materiales, textos y lecturas. Revista História Hoje, São Paulo, v. 7, n. 13, p. 6082, 2018.

GONZÁLEZ, Maria Paula. Saberes y prácticas docentes en historia: usos y lecturas del Nunca Más. Revista Escuela de Historia, Salta, v.10, n. 2, p. 1-24, jun./dez. 2011.

HACHMANN, Juliana. Imprensa64.pro.br: materiais didáticos sobre o golpe de estado de 1964 por meio da imprensa brasileira. 175 f. 2016. Dissertação (Mestrado Profissional em Rede Nacional PROFHISTORIA) - Centro de Ciências Humanas e da Educação, Universidade Estadual de Santa Catarina, Florianópolis, 2016. 
JELIN, ELIZABETH. Memoria y democracia: una relación incierta. Revista Mexicana de Ciencias Politicas y Sociales, Cidade do México, ano LIX, n. 221, p. 225-242, maio/ago. 2014.

KALLÁS, Ana Lima. O debate público de professores historiadores acerca da ditadura pós-1964 no Brasil: ensino de história, memória e usos públicos da história recente (1985 - 2015). 361 f. 2020. Tese (Doutorado em História) Instituto de História, Universidade Federal Fluminense, Niterói, 2020.

LIBRENZA, Isadora Ritterbusch. Tocando na ferida: gênero e ditadura no ensino de história através da análise de testemunhos. 87 f. 2018. Dissertação (Mestrado Profissional em Ensino de História) - Instituto de Filosofia e Ciências Humanas, Universidade Federal do Rio Grande do Sul. Porto Alegre, 2018.

MATTOS, Ilmar de. "Mas não somente assim!": leitores, autores, aulas como texto e o ensino-aprendizagem de História. Revista Tempo, Niterói, v. 11, n. 2, p. 5-16, 2007.

MONTEIRO, Ana Maria Monteiro. Aulas de história: questões do/no tempo presente. Educar em Revista, Curitiba, n. 58, p. 165-182, out./dez. 2015.

MOURA, Fernanda Pereira; SALLES, Diogo da Costa. O Escola Sem Partido e o ódio aos professores que formam crianças (des)viadas. Periódicus, Salvador, n. 9, v. 1, p. 136-160, maio/out. 2018.

NAPOLITANO, Marcos. Desafios para a história nas encruzilhadas da memória: entre traumas e tabus. História: Questões \& Debates, Curitiba, v. 68, n. 01, p. 1856, jan./jun. 2020.

NICOLAZZI, Fernando. A história da ditadura contada pelo Brasil Paralelo. [S.l.]: Sul21, 2019. Disponível em: https://www.sul21.com.br/opiniaopublica/2019/03/ahistoria-da-ditadura-contada-pelo-brasil-paralelo-por-fernando-nicolazzi/ Acesso em: 19 nov. 2020

NOGUEIRA, Marcia Barbosa. O ensino de história e as músicas de Chico Buarque de Holanda: da escuta à produção de sentidos históricos na Escola Estadual Engenheiro Palma Muniz, em Redenção - PA. 129 f. 2018. Dissertação (Mestrado Profissional em Ensino de História) - Campus Universitário de Araguaína, Universidade Federal do Tocantins, Araguaína, 2018.

NUNES, Fernando de Lima. Para não esquecer: ensino de história e empatia histórica a partir da escrita de biografias de desaparecidos políticos da ditadura civil-militar brasileira. 225 f. 2018. Dissertação (Mestrado Profissional em Ensino de História) - Instituto de Filosofia e Ciências Humanas, Universidade Federal do Rio Grande do Sul, Porto Alegre, 2018.

OLIVEIRA, Itamar Freitas; OLIVEIRA, Margarida Maria Dias de. Desafios do mestrado profissional na reinvenção do campo do ensino de história: uma avaliação preliminar dos programas de ensino de teoria da história e de história 
do ensino de história. CLIO: Revista de Pesquisa Histórica. Recife, v. 38, p. 27-47, jan./jun. 2020.

PACHECO, Danilo Mateus da Silva. Tempo de lembrar: memórias da ditadura e Ensino de História do Amapá. 136 f. 2018. Dissertação (Mestrado Profissional em Ensino de História) - Fundação Universidade Federal do Amapá, Macapá, 2018.

PEREIRA, Mateus Henrique de Faria. Nova direita? guerras de memória em tempos de comissão da verdade (2012-2014) Varia Historia, Belo Horizonte, v. 31, n. 57, p. 863-902, set./dez. 2015.

PIRES, Elaine Prochnow. Ideias históricas de jovens do ensino médio sobre representação das mulheres no ensino de história do Brasil: estudo de caso. 191 f. 2016. Dissertação (Mestrado Profissional em Ensino de História) - Centro de Ciências Humanas e da Educação, Universidade do Estado de Santa Catarina, Florianópolis, 2016.

QUEIROZ, Deborah da Silva. Memória da resistência à ditadura militar brasileira: guia para utilização de filmes em sala de aula. 219 f. 2016. Dissertação (Mestrado Profissional em Ensino de História) - Escola de História, Universidade Federal do Estado do Rio de Janeiro, Rio de Janeiro, 2016.

QUINAN, Licia Gomes. As memórias dos jovens sobre a ditadura civil-militar e a função social do historiador/ professor. 84 f. 2016. Dissertação (Mestrado Profissional em Ensino de História) - Instituto de História, Universidade Federal do Rio de Janeiro, Rio de Janeiro, 2016.

RAGGIO, Sandra. Transmisión de la memoria: la experiencia en el encuentro con Otros. El largo proceso de institucionalización de la memoria en la escuela. Aletheia, La Plata, v. 7, n. 14, p. 1-12, abril 2017.

ROCHA, Helenice. A ditadura militar nas narrativas didáticas. In: ROCHA, Helenice, REZNIK, Luis e MAGALHÃES, Marcelo de Souza. Livros didáticos de história: entre políticas e narrativas. Rio de Janeiro: FGV Editora, 2017. p. 245268.

RODRIGUES, Eric Freitas. Tecnologia, inovação e ensino de história: o ensino híbrido e suas possibilidades. 97 f. 2016. Dissertação (Mestrado Profissional em Ensino de História) - Instituto de Ciências Humanas e Filosofia, Universidade Federal Fluminense, Niterói, 2016.

SILVA, Vinícius Ávila. Trilhas da ditadura civil-militar na cidade do Rio de Janeiro: roteiro para Educação em Direitos Humanos. 95 f. 2019. Dissertação (Mestrado Profissional em Ensino de História) - Centro de Educação e Humanidades, Faculdade de Formação de Professores, Universidade do Estado do Rio de Janeiro, São Gonçalo, 2019.

SILVA, Luiz Gabriel da. Repressão e resistência na ditadura civil-militar: construção de site temático para o ensino de história local (Curitiba - PR). 151 f. 
2018. Dissertação (Mestrado Profissional em Ensino de História) - Universidade Federal do Paraná, Curitiba, 2018.

SILVA, Daniel Pinha. O lugar do tempo presente na aula de história: limites e possibilidades. Revista Tempo e Argumento, Florianópolis, v. 9, n. 20, p. 99-129, jan./abr. 2017.

SOSA, Júlio Cezar Gonçalves. Ensino de História: o olhar dos e das estudantes do nono ano, da EEEM Lilia Beves (Rio Grande, RS), sobre a ditadura civil militar. 152 f. 2016. Dissertação (Mestrado Profissional em Ensino de História) - Instituto De Ciências Humanas e da Informação, Universidade Federal Do Rio Grande, Rio Grande, 2016.

TURIN, Rodrigo. Entre o passado disciplinar e os passados práticos: figurações do historiador na crise das humanidades. Tempo, Niterói, v. 24, n. 2, p. 186-205, maio/ago. 2018. 